\title{
A REVIEW OF ACTION RESEARCH - AN APPROACH FOR CHANGE AND DEVELOPMENT IN MANAGEMENT STUDY
}

\author{
NGUYEN THI BICH TRAM \\ University of Liverpool, United Kingdom - Email: tram.nguyen@liverpool.ac.uk
}

(Received: April 7, 2016; Revised: June 15, 2016; Accepted: October 10, 2016)

\begin{abstract}
This paper introduces action research as an approach for change and development in management research based on its outstanding characteristics and discusses the application notion of action research by critically reviewing its strengths and limitations as well as representing an example case to demonstrate how to employ it in practical setting. Finally, the author draws attention to bias avoidance in action research by introducing three effective practices to mitigate against sources of bias.
\end{abstract}

Keywords: action research; research method; bias avoidance.

\section{Introduction}

There are several research methods in social science study and each research method will be a tool in researcher's hand in the duty of capturing "the truth". Researchers will choose an appropriate method based on analyzing its usefulness for the research design. One of the best way to evaluate whether a research method is a useful tool is its capability of producing practical impacts on society. As known as a methodology for change and development, action research has its proven utility by the emergent recognition as research oriented toward the enhancement of direct practice (Somekh, 2005). It brings changes to communities or organizations and contributes to human knowledge with the guideline to practice based on the findings of the research process. Therefore, these abilities of action research could make it become a useful tool in management research where research problems are diversity, emergent and action-oriented.

The first part of the paper articulates what action research is, what its characteristics are in order to introduce a general view of action research. Additionally, one of the intentions of this paper is to critically review particular strengths and limitations associated with applying action research in practical setting. An example case of action research is presented to illustrate how to employ action research in a non-profit organization to improve the practical management of collaboration. At the end, the author draws attention to bias avoidance in action research by introducing some methods to mitigate against it.

\section{An overview of action research}

Kurt Lewin (1946) first coined and defined the term "action research" as a mean of social change. He explained action research as "a comparative research on the conditions and effects of various forms of social action and research leading to social action" by using "a spiral of steps, each of which is composed of a circle of planning, action and fact-finding about the result of the action" (Kurt, 1946). Up till now, numerous conceptions and definitions of action research have been presented in the literature. In this paper, I adopt Reason and Bradbury's definition (2008):

Action research is a participatory process concerned with developing practical knowing in the pursuit of worthwhile human purposes. It seeks to bring together action and reflection, theory and practice, in participation with 
others, in the pursuit of practical solutions to issues of pressing concern to people, and more generally the flourishing of individual persons and their communities (p.8).

In a simple term, I suppose that action research means the collaboration between researchers and participants in order to tackle key problems in their communities or organizations through learning by doing and doing by learning with regard to the combination of idea and practice, action and reflection. The purposes of action research are to generate practical knowledge that is useful to people in conducting of their ordinal lives, to increase well-being of human communities, and to liberate the human in searching for a better, freer world (Reason and Bradbury, 2008). With these purposes, action research becomes popular among a variety of applied disciplines such as education, health and social care, women's issues, organizational development, management etc.

Action research is a useful methodology due to its distinctive characteristics compared to other research methods. Firstly, action research process is a cyclical nature that has four steps: plan, act, observe, and reflect, which is presented as a coherent sequence of activities. This model is based on Kurt Lewin's work, explicated by Kemmis and McTaggart (1988) (Figure 1).

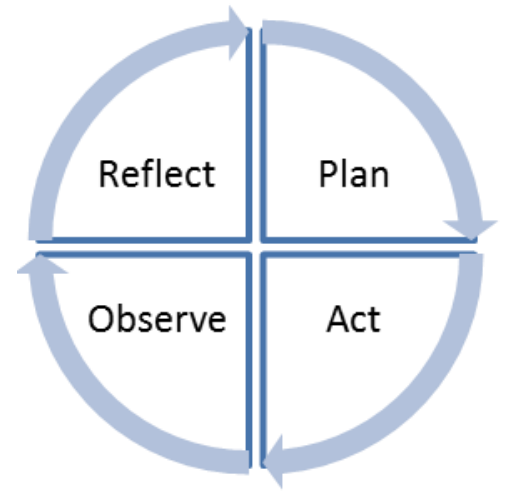

Figure 1. Cyclical action research process

Although it looks simple, the process has proven ability for helpful, continuous and iterative learning grounded on experiences of the critical reflection on the process and the outcomes. The process is then revised and extended by Elliott (1991, 2010) and numerous researchers with more detailed and restrictive form in order to become a considered deliberative process. This characteristic emphasizes action research's commitment to a process of research in which the application of findings and an evaluation of their impact on practice become part of a cycle of research (Denscombe, 2010).

Secondly, in the literature, the practical nature is considered as the defining characteristic of action research thanks to the need of solving real-world problems in natural setting. Action research links action with research based on the integration instead of a two-stage process in which research is carried out first by researchers and then in a separate second stage the knowledge generated from the research is applied by practitioners (Somekh, 1995). Reason and Bradbury (2008) confirmed this characteristic of action research that contributes to the realm of practical understanding including decisions and actions by practitioners in order to improve present situations.

The other distinctive characteristic of action research is participative because it requires action researchers to involve them as equal partners in the research process. There is continuous cooperation between researchers and practitioners in a spirit of collaboration and co-inquiry implied in action research, whereby research is constructed with people, rather than on or for them (Abraham et al., 2014). Thus, participative democracy becomes essential principle in action research. Denscombe (2010) acknowledged that action researchers shift their powers of control in the direction of democratizing the research process toward practitioners. In other words, action research encourages participants to be collaborators in the research rather than being subjects of it in respect of their knowledges and experiences.

Apart from the aforementioned characteristics of action research, there are four factors that help to modify the theory of the action research process as presented in Shani and Pasmore's work (1985), including 
contextual factors, quality of relationships, quality of the action research process, and outcomes of action research effort. Contextual factors set the context of the action research such as individual and shared goals, organizational characteristics and environmental factors. The second factor is the quality of relationships between members and researchers. Quality of action research process is involved in the inquiry process and the implementation process. The last factor is outcomes of action research related to some level of sustainability and the development of self-help, competencies out of action, and the creation of new knowledge of the inquiry. These factors should be in a close relation with each other in the research process as the Figure 2.

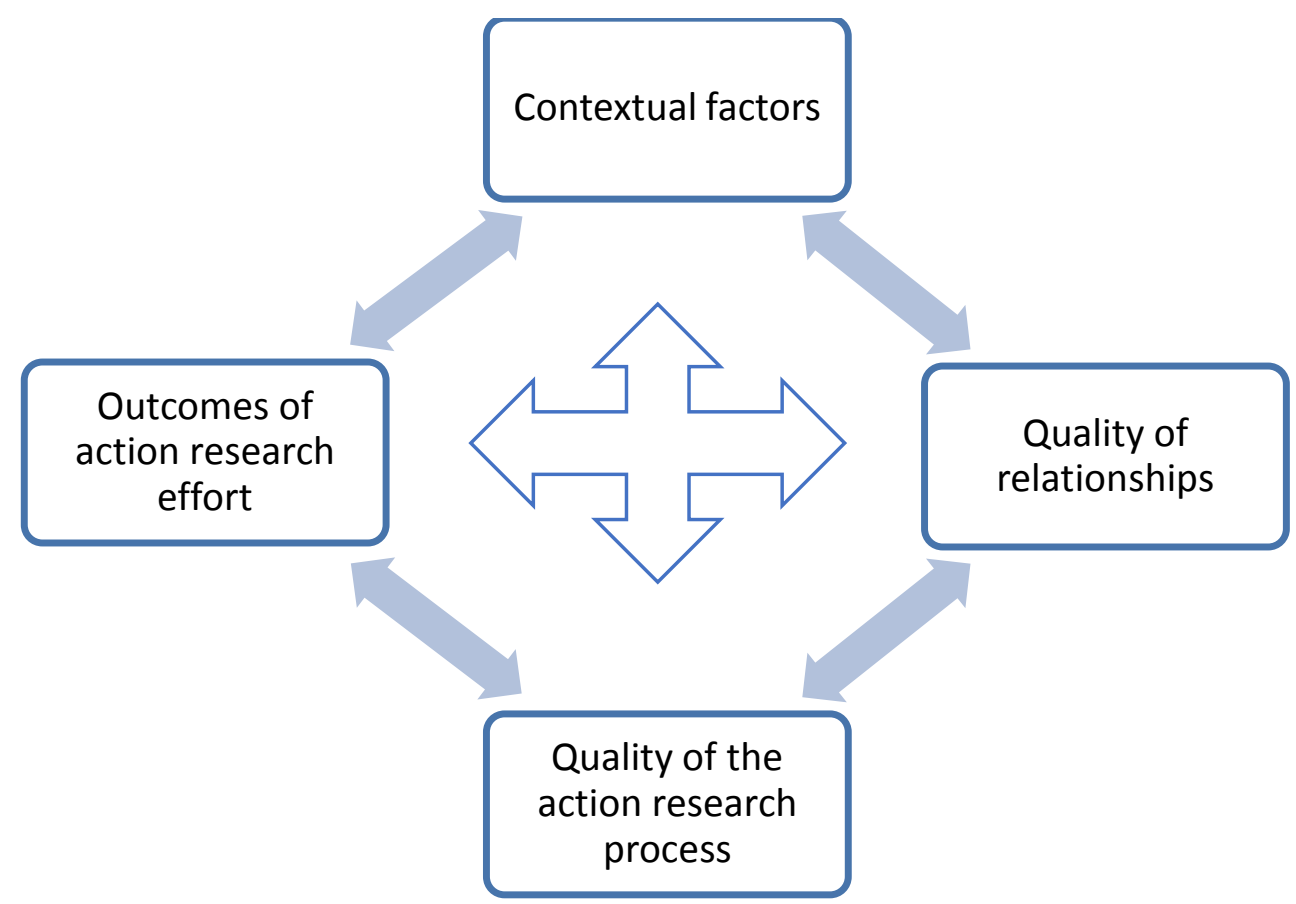

Figure 2. Complete theory of action research (Shani and Pasmore, 1985:444)

\section{Advantages of action research}

Bruce (2004) stated that "action research is one of the few research approaches that embraces principles of participation, reflection, empowerment and emancipation of people and groups interested in improving their social situation or condition". Thank to these principles, the use of action research has significantly arisen in a variety of research contexts such as education, health care, women's issue, etc. Management research is a tool to develop knowledge about organizational aspects and study new management phenomena (Alvesson and Deetz, 2000). Indeed, there are several action researchers have used this approach for management study in the literature. In this paper, I could not introduce all arguments explained why action research is used for management study. Therefore, some highlighted strengths of action research related to the abilities to solve immediate problems, to make change and to implement innovation are presented to argue that this approach could be one of the suitable methodologies for management research.

The research problems in management research are diversity and depended on the rising needs of each organization, for example, strategy, control, cooperation, optimization issues, etc. Action research is appropriate for focusing on solving immediate problems of organization since it is "research in action" rather than "research about action". 
It is an emergent inquiry process that engages in real organizational issues or knowledges in action rather than those being created particularly for the purposes of research as other research methods (Abraham et al., 2014). For that reason, the objectives of action research are usually more specific and out of praxis. It concentrates on solving immediate problems by producing practical solutions or the guidelines for the best practice (Denscombe, 2010), which is a distinguishing advantage of action research in comparison with other forms of research. This is one of the main reasons why Touboulic and Walker's (2016) confirmed that this pragmatic orientation of action research is particularly suitable for an applied field such as sustainable supply chain management where arising problems are often chaotic, crosssectional and essentially concerned with the flourishing of individuals and organizations in their article. Gummesson (2000) also confirmed that from a management perspective, action research is the most demanding and far-reaching method of doing research based on his experiences in conducting several case studies. By contrast, there are some researchers disagreed with this argument, for instance, Cooperrider and Srivastva (1987) criticized the view of action research as a form of problem solving. They doubted underlying assumptions about the nature of action research, which are grounded on practical and technical views of organizations as problems to be solved. Therefore, they suggested appreciative inquiry as a form of action research which focuses on building what is already successful instead of what is deficient (Coghlan and Brannick, 2014). However, Whyte (1989) argued that in organizational research, the research literature in any single discipline provides a very inadequate base for solving important practical and theoretical problem. He stated that to gain a firmer base, we need to be able to integrate information and ideas in our own discipline with technical information and ideas relevant to the organization studied.
In doing research, every researcher desires to contribute human knowledge by creating practical impacts. In the case of action research, researchers' contribution is making change, which is a vital task of conducting management research from my point of view. Coghlan and Brannick (2014) agreed that action researchers are not simply observing something happening; they are actively working at making it happen. By ideally involving researchers and practitioners working together to achieve complex real-life aims, action research not only make changes for a single individual, but also achieve changes that might affect or influence others (Townsend, 2013). The aims of action research will be defined by the participants' needs and the researcher's involvement in the process is to support (Schein, 1995). As a result, it provides a powerful means of improving and enhancing practice with regard to the agreement and commitment of those affected by involving them directly in its reflective cyclical process. These involvement enhance action research approach in raising different perspectives since these perspectives become the central focus of the research process and help researchers to conceive the present situation. Researchers will have chances to engage more deeply in the research process and see its potential to address management problems. One of the common kinds of changes involved in action research is the level of professional self-development. Denscombe (2010) referred this change could entail a certain degree of reflection and add the systematic and rigorous data to the resources that the professional can use to achieve the improvement in practice. This strength therefore establishes a solid foundation in the service of human flourishing.

As a methodology for change and development, the significant strength of action research is the ability of implementing innovation while tailoring to meet local needs. Innovation in science is defined as a question of applying, exploring or exploiting the basic 
leaps forwards in knowledge (Gustavsen, 2005). According to Whyte (1989), it should be beneficial for action researchers to have a research strategy that maximizes the possibility of encountering "creative surprises" when academia gets out of our academic morass and work with practitioners whose knowledge and experience contribute far more to our own learning. Formed on each community or organization's distinctive features, action researcher is engaged in an explicit program to develop new solutions that change existing practice and then test the feasibility and properties of the innovation via action research process (Kaplan, 1998). Gustavsen and his colleagues (2008) have demonstrated this strength of action research in their work of helping promote the quality of working life in Scandinavia over the past 40 years. In this work, there are national agreements among all relevant stakeholders to test emergent theory and practice in the efforts to look for practical guidelines to the future to gain knowledge under the organizational conditions.

\section{Challenges in using action research}

Like any research methods, action research also has some limitations. In the methodological notion, it might be a timeconsuming process. Although action research is a beneficial tool for researchers, it takes a lot of time to conduct. Action researchers will have to deal with a series of flexible cycles involving practice and research, which is unlikely to stop owing to the cyclic nature of action research. This limitation could be the explanation for the reason why action research is usually used for longitudinal studies in the management study literature. For example, Middel et al. (2006) spent over 15 months in conducting "Action Research in Collaborative Improvement". Other notable examples of time-consuming process are "Conceptualizing operations strategy processes", in which Rytter et al. (2007) took nearly five years to complete and action research programs in Scandinavia, in which Gustavsen et al. (2008) spent over 40 years. A timeline for action research process will depend on research's requirements and objectives. For that reason, action researcher needs to take this element into account and carefully estimate timeline of the study to overcome it. I suppose that this limitation of action research somehow prevents researchers from choosing this approach for management study under pressure to find out a quick-response solution for their problems.

Moreover, the requirements for researchers are very complicated in applying this research method in management study. On the one hand, action research involves exploratory engagement with not only specific knowledge of management field but also a wide range of existing knowledge drawn from different disciplines, namely psychology, philosophy, sociology and other fields of social science in order to test its explanatory power and practical usefulness (Somekh, 2005). It encounters considerable received wisdom in both academia and among social change and development practitioners (Reason and Bradbury, 2008). As a result, researchers act as "a bridge" between industry and the academy through extensive knowledge of the company being studied and the research process (Coghlan and Brannick, 2014). On the other hand, due to complex processes, action researchers are responsible for multiple tasks at different stages of the research process, for example, planner, observer, listener, practitioner, workshop tutor, interviewer, etc. To cope with these tasks, action research processes require confident and experienced researchers.

The key concept of action research is the partnership between researchers and participants. Participants in action research process could involve both external stakeholders such as customers, clients, local community or even competitors and internal stakeholders such as individuals, groups and departments of organizations. This is either the advantage or the limitation of action research. During the research process, Kathryn and Gary (2005) claimed that 
Academics (outsiders) want to understand what it is like to be an insider without "going native" and losing the outsider's perspective. Practitioners, because they are "native" to the setting, must work to see the taken-forgranted aspects of their practice from an outsider perspective. This is further complicated by the fact that many academic researchers have, in fact, been practitioners and are, therefore, in some sense both insiders and outsiders (p.5).

In other words, the collaboration of both insiders and outsiders might cause several discomforts and difficulties for researchers to "co-labouring" with their partners related to numerous differences in their perspectives, ideas, experiences and personalities. Sumara and Luce-Kapler (1993) described these difficulties are "unpredictable, often uncomfortable, challenging, yet always infused with the possibility of what the next page will bring". In their study, Touboulic and Walker (2016) also raised the dilemmas related to broader issues of resistance to participation and resistance to change from participants. In Transferring Insight to Practice Project to develop theory of the complexity of collaboration practice, Huxham and Vangen (2003) recognized this problematic issue in collaborating with members of organizations since they reacted very negatively to the research sessions. Hence, it is difficult to evaluate completely all obstacles from this collaboration on the field.

An important task for management research is to understand and develop better models of management action that situate management in an 'organizational' rather than 'purely' economic context (Ghoshal and Moran, 1996). Therefore, action researchers closely approach to study management phenomenon in its natural setting in research processes. By acting within or changing setting, action researchers through their presence might "contaminate" the naturalistic inquiry (Kathryn \& Gary, 2005). Even though this is considered as a common limitation in qualitative study, other qualitative research methods have to deal with it such as ethnography. This weakness still poses difficulties for the notion of bias avoidance in action research and influences the validity of action researchers' findings. In addition, when researchers approach research problems too close, they could limit the scope and scale of research because of its highly applicable feature for local needs and the necessary involvement of the practitioners. These issues might affect the representativeness of the findings and the extent to which generalizations can be made on the basis of the results. Many researchers expressed their concerns about action research's ability to transfer its results to other settings and claimed that action research is only appropriate for small-scale social research projects (Kathryn \& Gary, 2005; Denscombe, 2010). However, Gustavsen et al. (2008) presented an example of the successive widening of action research scope from small workplaces to substantial regions in Scandinavia through establishing development partnerships of several organizations namely industries, unions and government engaged in shared learning. This limitation is still under debate among researchers.

\section{Bias avoidance in action research}

Action researchers are interested in whether knowledge generated from the research is valid or trustworthy as the same as other researchers. Therefore, it would be beneficial to address bias since it could threat the credibility and accuracy of the research. Kathryn and Gary (2005) supposed bias is natural and acceptable in action research as long as they are critically examined instead of being ignored. Accordingly, the key concern is how to examine and mitigate against it in action research. It goes without saying that all researchers enter research with perspectives drawn from their own experiences. It is necessary for them to try their best to assess and locate potential biases in research processes. There is a variety of current techniques for qualitative researchers as well 
as action researchers to deal with bias. However, I call attention to three specific practices that are popular in managing research bias.

Firstly, action research integrates with practice more than other research methods. As suggested by many researchers in the literature, it is necessary to build a critical reflexivity into the research process. A critical reflexivity requires researchers are always critical about practice and open to new ways of thinking and doing to guarantee the production of truth (Shenton, 2004). Actually, the most celebrated practices of qualitative research is self-reflexivity. Tracy (2010) stated that self-reflexivity is honesty and authenticity with one's self, research, and audience, which encourages researchers to assess their own biases, motivations, and other issues related to their researches. She also recommended that this practice could begin from very early stage of research design through negotiating access and trust, data collection, analysis, and presentation.

Secondly, as suggestion of Lincoln and Guba (1985), the effectiveness of member reflection should be considered to bolster a study's credibility. Member reflections encourage researchers to share and dialogue with participants about the study's findings, and it provides opportunities for questions, critique, feedback, affirmation, and even collaboration (Tracy, 2010). There are many forms of member reflections, such as member checking, member validation, and host verification that refer to methods of "taking findings back to the field and determining whether the participants recognize them as true or accurate" (Lindlof and Taylor, 2002). This method strengthens the collaboration between academics and practitioners in the research process and it is a good way to manage bias.

Finally, triangulation is familiar with qualitative researchers as an effective mitigation against research bias. Denzin (1978) assumed that if two or more sources of data, theoretical lens, multiple types of data, or researchers converge on the same conclusion, then the conclusion is more credible. Some researchers argued Denzin's viewpoint that triangulation does not necessarily result in improved accuracy. On the contrary, Tracy (2010) argued that different viewpoints of problems might help broaden scope, extend understanding, and encourage consistency in interpretation. In support to this practice, Rytter et al. (2007) collected multiple types of data via observations, interviews, conversations, documents and self-reflections to capture different perspectives of workforce facilitator, operations experts and active participants in their study.

\section{An case example of action research:} The Transferring Insight to Practice Project

To modify an example of using action research in management study, I introduce the Transferring Insight to Practice (TIP) Project in developing theory of the complexity of collaboration practice by Chris Huxham, University of Strathclyde and Siv Vangen, The Open University, United Kingdom. Their paper has published on Organizational Research Methods Journal that is a 4 stars ranked journal in ABS (2015) with over 4 points of Impact Factor.

Research contexts: The broad aim of their study contributes to a growing understanding of action research methodology for researching organizations. The TIP case is their research program in the management of inter-organizational collaboration, which has now spanned more than 12 years. Huxham and Vangen (2003) wanted to gain a theoretical understanding that could inform the practical management of collaboration that has been carried out within the action research methodology. The study was the collaboration between the authors and two senior managers of the Poverty Alliance. The Poverty Alliance (PA) is a collaborative alliance with a membership of approximately 100 public and non-profit organizations in the West of Scotland. 
Goal: The goal of their study was to explore why collaboration so often seems to produce disappointing output in practice and what this means for the way in which practitioners involved in collaborations might act in order to increase their effectiveness. From researchers' perspective, Huxham and Vangen (2003) tried to identify key areas of concern that cause anxiety or reward to practitioners involved in collaboration. From action's perspective, the PA managers' aim was to develop tools for direct use in PA activities and partly from a sense that a part of their role as alliance managers with extensive experience in managing and working in collaborative settings should be to disseminate their understanding of effective collaboration to a wider audience.

Research question: "How can methods be created that will allow the complexity of their theoretical and practical understandings of the practice of collaboration to be transferred to and used productively by others involved in collaborations without their being present?"

Collaborative action:
There are two parts of the project. In the first part, the managers' participation were the central discussion of the research issues. The process included a series of workshops involving the authors and two managers in which ideas, based on theory and experience, were tossed around. Following each workshop, Huxham and Vangen (2003) produced a detailed set of notes that formed one of the main data sets for the research. These were reviewed and further discussed and developed in the subsequent workshop. This process is represented by the "inputs" box and the central cycle of Figure 3. This stage last for 3 years and the result was a detailed set of interlinked design principles for transferring theoretical insight about collaboration to practice, including (a) the variation among participants typically involved in collaboration and hence among potential users of the TIP; (b) the nature of the collaboration theory and, in particular, to ways of conveying its complexity that would be meaningful to users; and (c) the nature of the envisaged use in practice.

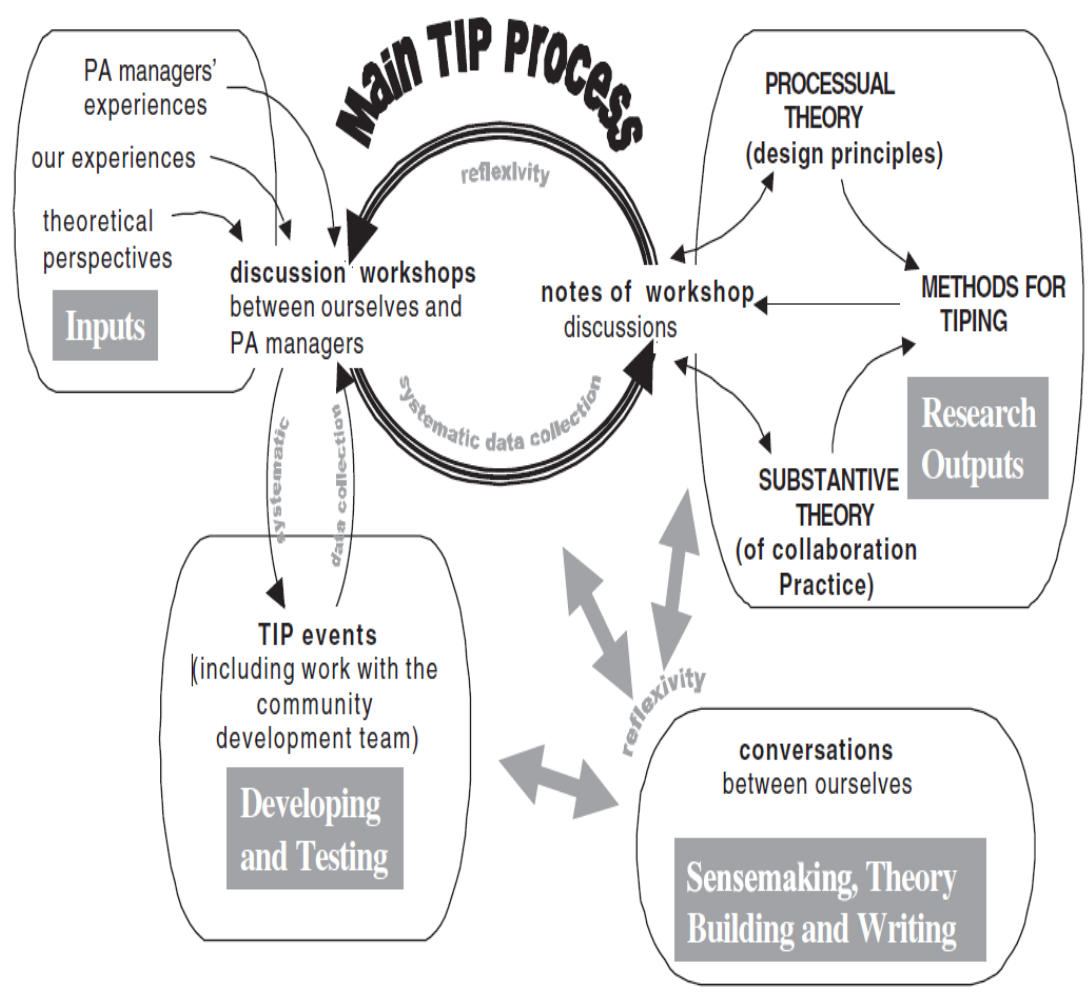

Figure 3. The action research process for the TIP Project (Huxham and Vangen, 2003) 
The second part of the project could be considered as a stage of trial from the first part's finding. The authors and PA managers worked with the Community Development Team to support them in promoting and providing training for local groups on effective collaboration with local authorities, health boards, enterprise companies and the private sector. The work with the team began with a series of awareness-raising events in which the aim would be to try out processes designed to support team members toward gaining a substantive understanding of collaboration practice. Tool development and evaluation work followed then. In the second part of the project, Huxham and Vangen (2003) had to deal with many difficulties and unexpected problems because the Team reacted very negatively to the research sessions. However, these problematic issues have led to refinements of the processual theory embodied in the design principles.

Research outcomes: the project has delivered significant results, namely the embodiment of the processual theory about collaboration, and the development of the substantive theory as a by-product. Together, the three elements informed the development of methods for the TIP as indicated in the "research outputs" box of the Figure 3. To that end, the case demonstrates how action research can be used to tackle the emerging research aims in the PA. It represents one process through which the relationship between practitioners and researchers can be designed to support both action and research agendas.

\section{Conclusions}

Since there is not enough space for a full review of all viewpoints found in the action research literature, the paper is limited to go some way towards enhancing our understanding of action research approach in management study, drawing on the existing literature and illustrated by the TIP project in developing theory and improving the practical management of collaboration (Huxham \& Vangen, 2003). The aim of the paper is to have changed the representations of action research for scholars and others involved in management research. In brief, action research is one of the most participatory research which enables researchers gaining deeper understanding of science knowledge and introducing practical solutions for immediate problems. There are three distinctive characteristics of action research are participation, practical nature, and cyclical process, which make action research is highly distinctive compared to other research methods. In this paper, the strengths of action research are listed to argue that action research could be an appropriate method for management study such as an emergent inquiry, the abilities to make change and implement innovation. However, the drawbacks of action research are also addressed such as time consuming, complicated requirements for researchers, "co-laboring" issue, and the ability of generalization. In addition, the case example of action research is presented to demonstrate how to employ it in the organizational research project. At the end of the paper, there is the discussion of bias avoidance since bias in action research could affect findings of studies. The author also introduces three potential solutions to manage research bias that could be used in action research approach

\section{References}

Abraham, B. et al. (2014). Action and Collaboration Between Scholarship and Practice. OD Practitioner, 46 (4), 35-39.

Alvesson, M., \& Deetz, S. (2000). Doing critical management research. Sage.

Bruce, L. B. (2004). Action Research. Qualitative Research Methods for the Social Sciences. Pearson Education, $5^{\text {th }}$ Edition. 
Coghlan, D., \& Brannick, T. (2014). Doing action research in your own organization. Los Angeles: SAGE, 2014.

Cooperrider, D. \& Srivastva, S. (1987). Appreciative inquiry in organizational life. Research in Organizational Change and Development, 1, 129-169.

Denscombe, M. (2010). The good research guide: for small-scale social research projects. Maidenhead: McGrawHill/Open University Press, 2010.

Denzin, N. K. (1978). Sociological methods: A sourcebook, $2^{\text {nd }}$ edition. New York: McGraw Hill.

Elliott, J. (1991). Action Research for Educational Change, Open University Press: Milton Keynes.

Elliott, J. (2010). Building social capital for educational action research: the contribution of Bridget Somekh. Educational Action Research, 18(1), 19-28.

Ghoshal, S. and Moran, P. (1996). Bad for practice: a critique of the transaction cost theory. Academy of Management Review, 21, 13-47.

Guba, E. G., \& Lincoln, Y. S. (1989). Fourth generation evaluation. Newbury Park, CA: Sage.

Gummesson, E. (2000). Qualitative Methods in Management Research, 2nd ed., Sage, London.

Gustavsen, B. (2005). Innovation and action research. International Journal of Action Research, 1(3), 267-289.

Gustavsen, B., Agneta H., and Thoralf U. Q. (2008). 4 Action Research and the Challenge of Scope. The SAGE Handbook of Action Research, $2^{\text {nd }}$ edition, 64 - 77. London, England: SAGE Publications.

Huxham, C. \& Vangen, S. (2003). Researching Organizational Practice Through Action Research: Case Studies and Design Choices. Organizational Research Methods, 6(3), 383-403.

Kaplan, R. S. (1998). Innovation Action Research: Creating New Management Theory and Practice. Journal of Management Accounting Research, 10, 89-118.

Kathryn, H. and Gary, L. A. (2005). 4 Quality Criteria for Action Research: An ongoing Conversation. The Action Research Dissertation: A Guide for Students and Faculty. SAGE Publications, Thousand Oaks.

Kemmis, S. and McTaggart, R. (1988). The Action Research Planner. Deakin University Press, Geelong, Victoria, $3^{\text {rd }}$ edition.

Lewin, K. (1946). Action Research and Minority Problems. Journal of Social Issues.

Lindlof, T. R., \& Taylor, B.C. (2002). Qualitative communication research methods, $2^{\text {nd }}$ edition. Thousand Oaks, CA: Sage.

Middel, R. et al. (2006). Action Research in Collaborative Improvement. International Journal of Technology Management, 33(1), 2006, 67-91.

Reason, C.P. and Bradbury, H. (2008). Introduction. The SAGE Handbook of Action Research, $2^{\text {nd }}$ edition, 1-11. London, England: SAGE Publications.

Rytter, N. G. et al. (2007). Conceptualizing operations strategy processes. International Journal of Operations \& Production Management, 27(10), 1093-1114.

Schein, E. (1995). Process consultation, action research and clinical inquiry: Are they the same? Journal of Managerial Psychology, 10(6), 14-19.

Shani, A.B. (Rami) and Pasmore, W.A. (1985). Organization inquiry: towards a new model of the action research process", in D.D. Warrick (ed.), Contemporary Organization Development: Current Thinking and Applications. Glenview, IL: Scott, Foresman, 438-448.

Shento, A. K. (2004). Strategies for ensuring trustworthiness in qualitative research projects. Education for Information, 22(2), 63-75.

Somekh, B. (1995). The Contribution of Action Research to Development in Social Endeavours: a position paper on action research methodology. British Educational Research Journal, 21(3), 34. 
Somekh, B. (2005). Action Research: A Methodology for Change and Development. Berkshire, GBR: McGraw-Hill Education.

Sumara, D.J. and Luce-Kapler, R. (1993). Action Research as a Writerly Text: locating co-laboring in collaboration. Educational Action Research, 1(3), 87-96.

Touboulic, A. \& Walker, H. (2016). A relational, transformative and engaged approach to sustainable supply chain management: The potential of action research. Human Relations, 69(2), 301-343.

Townsend, A. J. (2013). Action research: the challenges of understanding and changing practice. Maidenhead: McGraw-Hill Education.

Tracy, S. J. (2010). Qualitative Quality: Eight 'big tent' criteria for excellent qualitative research. Qualitative Inquiry, 16(10), 837-851.

Whyte, W. F. (1989). Advancing Scientific Knowledge Through Participatory Action Research. Sociological Forum, 4(3), 367. 